\title{
Pressure and Temperature induced Dual Responsive Molecular Crystals: Effect of Polymorphism
}

Ragaverthini Chinnasamy, ${ }^{a}$ Bhushan Munjal, ${ }^{\mathrm{b}}$ Raj Suryanarayanan, ${ }^{\mathrm{b}}$, Abdul Malik P. Peedikakkal, ${ }^{\mathrm{c}, \mathrm{d}}$ Manish Kumar Mishra, ${ }^{*, \mathrm{e}}$ and Soumyajit Ghosh*,a

aDepartment of Chemistry, SRM Institute of Science and Technology, Chennai 603203 , India

bepartment of Pharmaceutics, College of Pharmacy, University of Minnesota, Minneapolis, MN 55455, United States

'Department of Chemistry, King Fahd University of Petroleum and Minerals, P.O. Box 5048, Dhahran 31261, Saudi Arabia

d Interdisciplinary Research Center for Hydrogen and Energy Storage, King Fahd University of Petroleum and Minerals, Dhahran 31261, Saudi Arabia.

eDepartment of Chemistry (SAS), VIT University, Vellore-632014, Tamil Nadu, India

\section{Contents}

Materials and synthesis. S2

Supporting tables .S3-S4

Supporting figures S5-S12

BFDH Morphology of crystals $1 \mathrm{~b}$ and 2 $\mathrm{S} 13$

References 
<smiles>O=[N+]([O-])c1cc(/N=C/c2cc(Br)cc(Br)c2O)ccc1F</smiles>

(1)<smiles>O=[N+]([O-])c1cc(/N=C/c2cc(Cl)cc(Br)c2O)ccc1F</smiles>

(2)

$1=3,5$-dibromosalicylidine-4-fluoro-3-nitroaniline $(\mathbf{1} \mathbf{a}, \mathbf{1} \mathbf{b})$

2 = 3-bromo-5-chloro-salicylidine-4-fluoro-3-nitroaniline (2)

Figure S1. Chemical structures of the investigated compounds.

\section{Materials and synthesis}

\section{Experimental section}

\section{Materials}

All the compounds- 3,5-dibromosalicylaldehyde, 3-bromo-5-chloro salicylaldehyde, and 4fluoro-3-nitro aniline, were purchased from Sigma-Aldrich. Commercially available solvents were used as received without further purification.

\section{Single Crystal Preparation}

Crystals were synthesized by adding one equivalent each of the respective salicylaldehyde and 4-fluoro-3-nitro aniline in hot methanol followed by slow evaporation of the solution under ambient conditions. Single crystals were grown in the following organic solvents including 
methanol, ethanol, acetone and acetonitrile. Good diffraction quality crystals were obtained after 4-5 days.

\section{Crystal Dimension:}

\begin{tabular}{|c|c|c|c|c|}
\hline \multirow{2}{*}{ Crystal } & \multicolumn{3}{|c|}{ Crystal Dimension } & \multirow{2}{*}{ Morphology } \\
\cline { 2 - 4 } & Length & Width & Thickness & \\
\hline $\mathbf{1 a}$ & $4.5 \mathrm{~mm}$ & $0.045 \mathrm{~mm}$ & $1.75 \mathrm{~mm}$ & Needle-plate \\
\hline $\mathbf{1 b}$ & $5 \mathrm{~mm}$ & $0.460 \mathrm{~mm}$ & $0.060 \mathrm{~mm}$ & Acicular \\
\hline $\mathbf{2}$ & $5 \mathrm{~mm}$ & $0.493 \mathrm{~mm}$ & $0.050 \mathrm{~mm}$ & Acicular \\
\hline
\end{tabular}

\section{Crystal images of $1 \mathrm{a}, 1 \mathrm{~b}$ and 2}

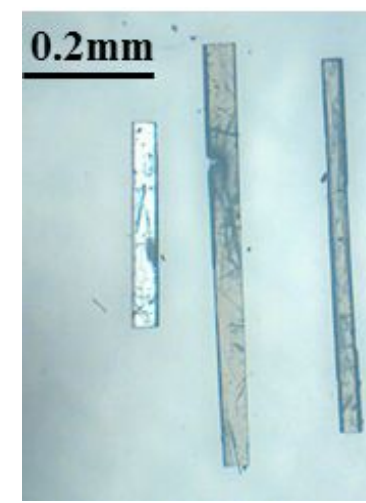

(1a)

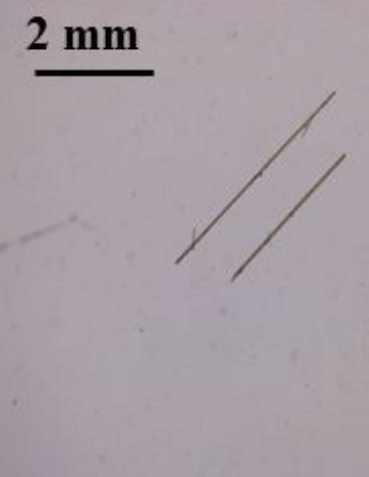

(1b)

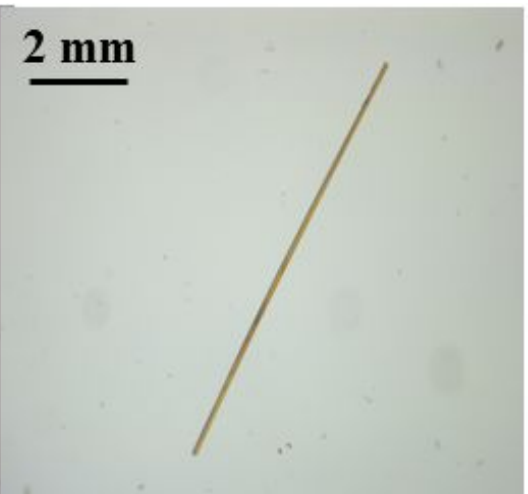

2

\section{X-ray Crystallographic Analysis}

Intensity data for 1a, $\mathbf{1 b}$ and $\mathbf{2}$ were collected on a Bruker AXS D8 Venture diffractometer using $\operatorname{MoK} \alpha(\lambda=0.71073 \AA)$ radiation generated by $\mathrm{I} \mu \mathrm{s}$ a microfocus tube and recorded with a Bruker AXS PHOTON II CPAD detector. The data collections were performed at $298 \mathrm{~K}$ using $\omega$-and $\varphi$-scans. Data collection: APEX3 Crystal Structure Analysis Package (Bruker AXS $),{ }^{1}$ cell refinement: SAINT, ${ }^{2}$ data reduction: SAINT, ${ }^{2}$ absorption correction: SADABS, ${ }^{3}$ structure solution: direct methods (SHELXT-2014) 4 and structure refinement: full-matrix leastsquares method on $F^{2}$ (SHELXT-2014) $)^{5}$ using SHELXT as the graphical user interface, ${ }^{6}$ molecular graphics: program XP (part of the SHELXT 6.14 program library). ${ }^{7}$ The crystal data 
as well as details of data collection and refinement of $\mathbf{1 a}, \mathbf{1 b}$ and $\mathbf{2}$ are summarized in Table S1.

Table S1: Crystallographic information table

\begin{tabular}{|c|c|c|c|}
\hline Compounds & $1 \mathrm{a}$ & $1 b$ & 2 \\
\hline Formula & $\mathrm{C}_{13} \mathrm{H}_{7} \mathrm{Br}_{2} \mathrm{FN}_{2} \mathrm{O}_{3}$ & $\mathrm{C}_{13} \mathrm{H}_{7} \mathrm{Br}_{2} \mathrm{~F} \mathrm{~N}_{2} \mathrm{O}_{3}$ & $\mathrm{C}_{13} \mathrm{H}_{7} \mathrm{BrClFN}_{2} \mathrm{O}_{3}$ \\
\hline Formula weight & 418.03 & 418.03 & 373.57 \\
\hline $\mathrm{T} / \mathrm{K}$ & $298(2)$ & $298(2)$ & $298(2)$ \\
\hline Crystal system & Monoclinic & Monoclinic & Monoclinic \\
\hline Space group & $P 2{ }_{1} / c$ & $P 2{ }_{1} / n$ & $P 2{ }_{1} / n$ \\
\hline $\mathrm{a} / \AA \AA$ & $11.7053(7)$ & 17.9739(14) & $17.944(3)$ \\
\hline $\mathrm{b} / \AA$ & $6.7179(4)$ & $7.3601(5)$ & $7.3085(10)$ \\
\hline $\mathrm{c} / \AA \AA$ & $17.7976(11)$ & $21.6795(14)$ & $21.374(3)$ \\
\hline$\alpha /{ }^{\circ}$ & 90 & 90 & 90 \\
\hline$\beta / \mathrm{o}$ & $96.013(2)$ & $104.779(4)$ & $105.368(8)$ \\
\hline$\gamma /{ }^{\circ}$ & 90 & 90 & 90 \\
\hline Volume $/ \AA^{3}$ & 1391.81(15) & $2773.1(3)$ & $2702.8(7)$ \\
\hline$Z$ & 4 & 8 & 8 \\
\hline$\rho$, g.cm ${ }^{-3}$ & 1.995 & 2.003 & 1.836 \\
\hline$\mu / \mathrm{mm}^{-1}$ & 5.846 & 5.868 & 3.262 \\
\hline $\begin{array}{l}\text { Reflections } \\
\text { collected }\end{array}$ & 23906 & 45024 & 41049 \\
\hline $\begin{array}{l}\text { Independent } \\
\text { Reflections }\end{array}$ & 3897 & 6894 & 6821 \\
\hline $\mathrm{R}_{\text {int }}$ & 0.0848 & 0.0907 & 0.0958 \\
\hline
\end{tabular}




\begin{tabular}{|c|c|c|c|}
\hline GOF & 0.975 & 1.139 & 0.913 \\
\hline Final $\mathrm{R}[\mathrm{I}>2 \sigma]$ & 0.0371 & 0.1029 & 0.0986 \\
\hline $\mathrm{R}_{1} / \mathrm{wR}_{2}$ & $0.1082 / 0.0925$ & $0.2286 / 0.2523$ & $0.3245 / 0.2770$ \\
& 2087423 & 1986676 & 1986709 \\
\hline
\end{tabular}

\section{Face indexing of the crystals:}

Face indexing of crystals of $\mathbf{1 a}, \mathbf{1 b}$ and $\mathbf{2}$ was done on a Bruker D8 Venture diffractometer (Bruker AXS Inc., Madison, Wisconsin) equipped with a Bruker PHOTON-II CMOS detector (Figure S2).

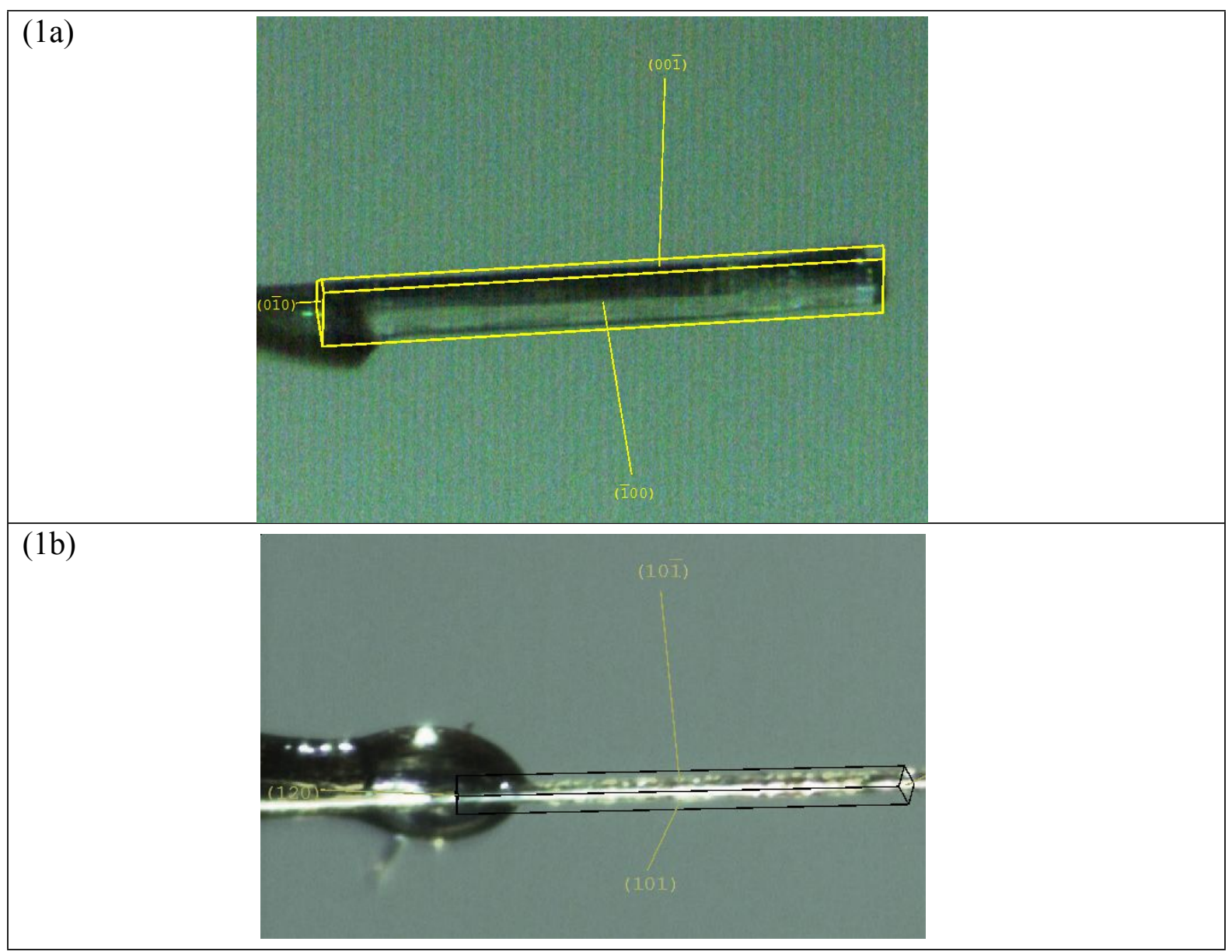




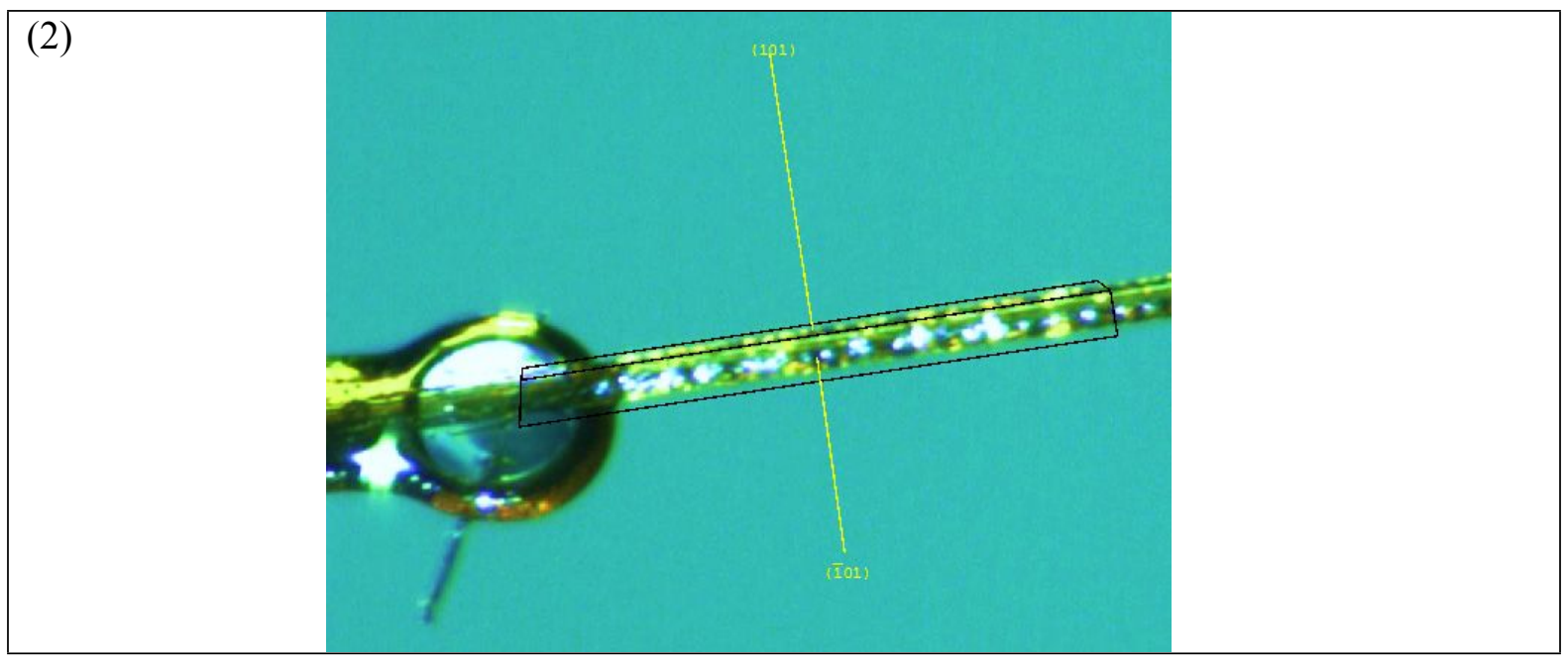

Figure S2. Face index of needle-shaped of $\mathbf{1 a}, \mathbf{1 b}$ and $\mathbf{2}$ crystals.

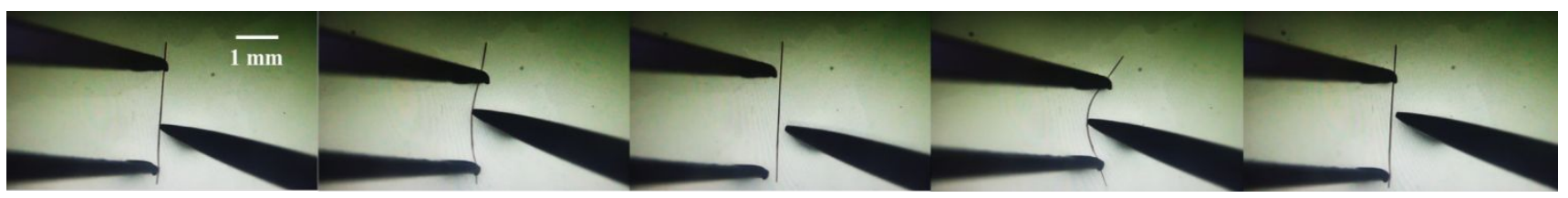

Figure S3. Snapshots of bending cycles of crystal $\mathbf{1 b}$.

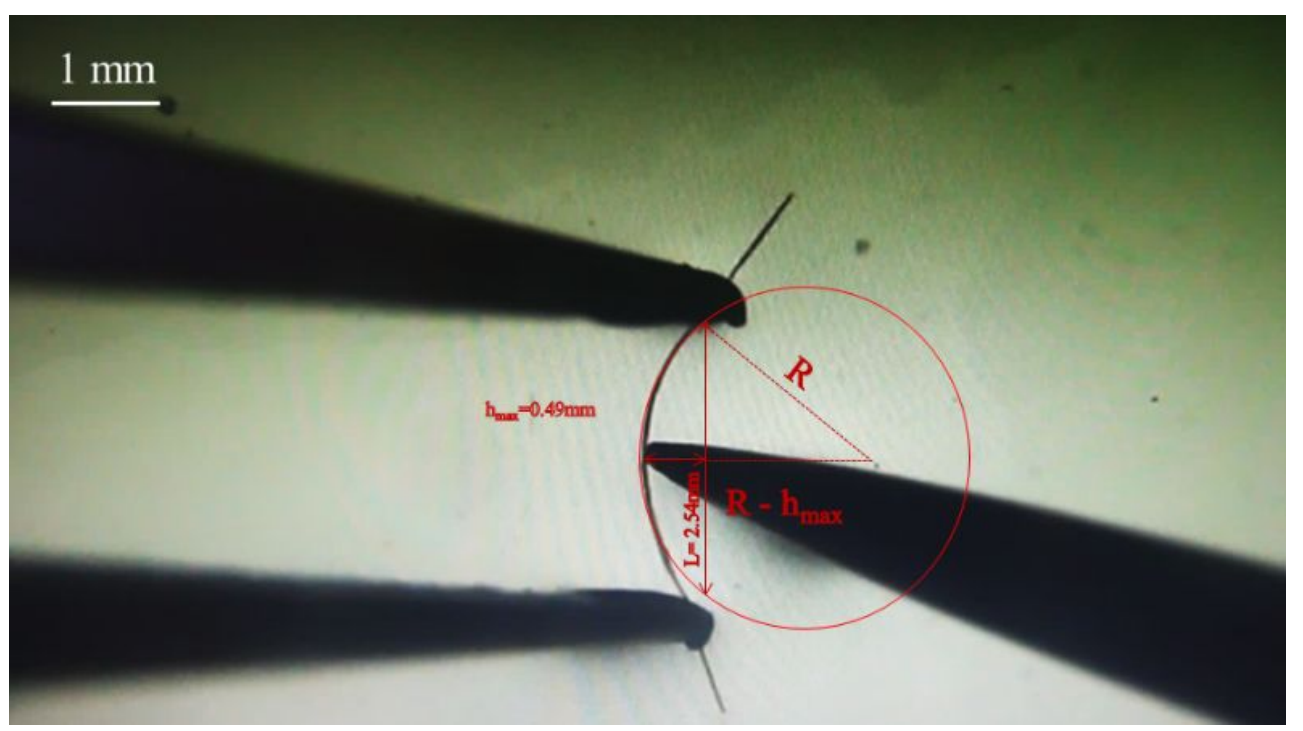

Figure S4. Bending strain calculation for crystal $\mathbf{1 b .}$ 
Elastic bending of $1 \mathrm{~b}$ using forceps and pin. The geometric construction indicates span length, $\mathrm{L}$, maximum displacement, $\mathrm{h}_{\max }$, and radius of curvature of the bent crystal. According to the Euler- Bernoulli beam theory ${ }^{8}$

$$
\begin{aligned}
& \mathrm{L}=2.54 \mathrm{~mm} ; \mathrm{h}_{\max }=0.49 \mathrm{~mm} ; \mathrm{t}=0.060 \mathrm{~mm} {\left[(0.49)^{2}+\left\{(2.54)^{2} / 4\right\}\right] } \\
& \mathbf{R}=\frac{0.98}{0.98} \\
&=\frac{(0.24+1.61)}{\mathbf{R}}=\frac{\mathbf{1 . 3 8} \mathbf{~ m m}}{}
\end{aligned}
$$

For a beam with thickness t,

$$
\varepsilon(\%)=\frac{t}{2 R}=\frac{0.060}{2.76} \times 100=\sim \mathbf{2 . 1 8 \%}
$$

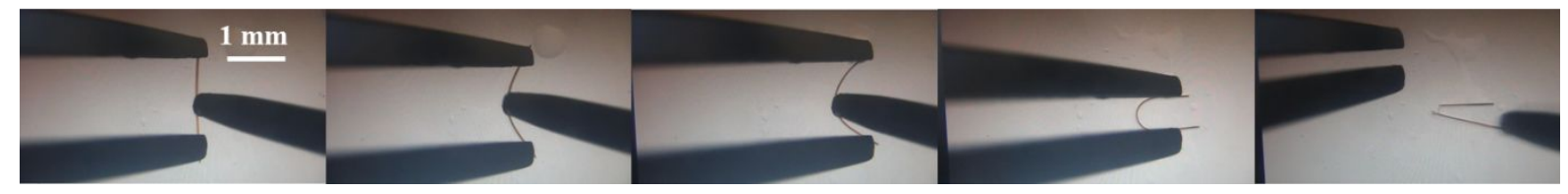

Figure S5. Snapshots of bending cycles of crystal 2

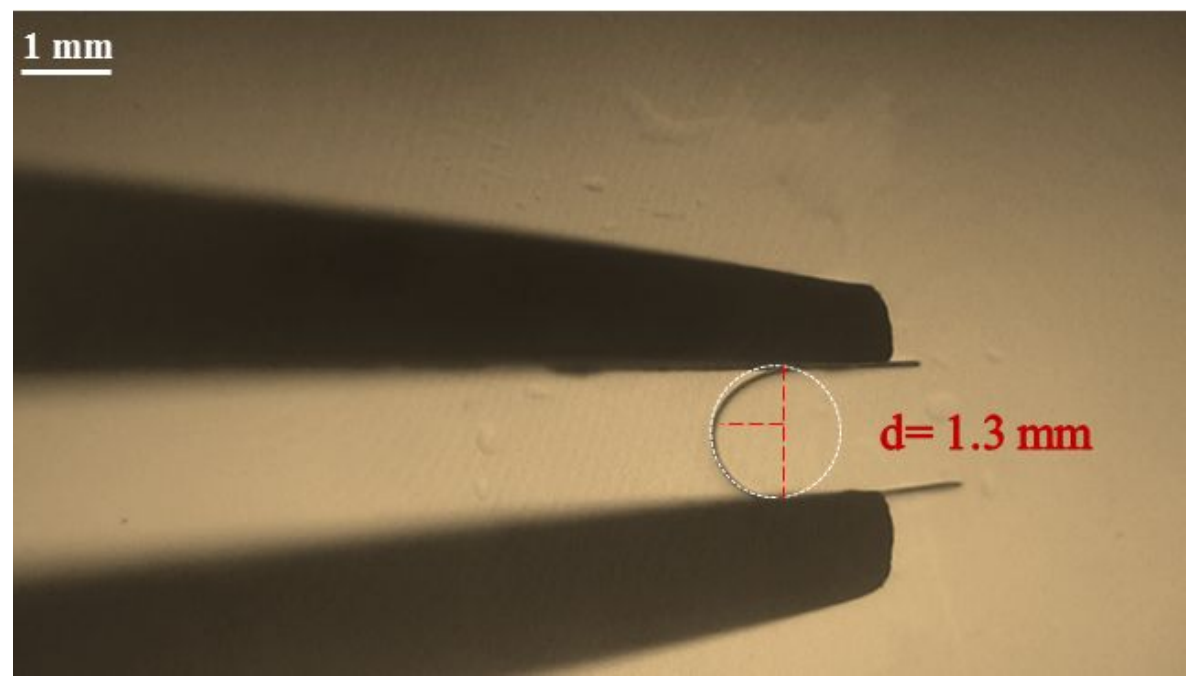

Figure S6. Bending strain calculation for crystal 2. 
$\mathrm{R}=\frac{D}{2}=\mathbf{0 . 6 5} \mathbf{~ m m}$, (where $\mathrm{D}$ is the diameter of the semicircle formed and so radius is $\frac{D}{2}$ )

For a beam with thickness t,

$\varepsilon(\%)=\frac{t}{2 R}=\frac{0.05}{1.3} \times 100=\sim \mathbf{3 . 8 5} \%$

where ' $\varepsilon(\%)$ ' is the elastic strain of the crystal, ' $t$ ' is the thickness of the crystal and ' $R$ ' is the radius of the semicircle formed by bending the crystal

\section{Differential scanning Calorimetry (DSC)}

A differential scanning calorimeter (DSC 214 Polyma) was used. Samples ( $\sim 3 \mathrm{mg}$ ) were placed in sealed aluminium pans, crimped hermetically and heated from $40-250{ }^{\circ} \mathrm{C}$ at $10{ }^{\circ} \mathrm{C} / \mathrm{min}$ under dry nitrogen purge of $40 \mathrm{ml} / \mathrm{min}$. Figures S7, S8 and S9 depict the heating curve of crystals 1a, $1 \mathrm{~b}$ and 2, respectively. For temperature cycling experiments, samples were first heated to 250 ${ }^{\circ} \mathrm{C}$, cooled back to $50{ }^{\circ} \mathrm{C}$, reheated to $250{ }^{\circ} \mathrm{C}$ and finally re-cooled to $50{ }^{\circ} \mathrm{C}$.

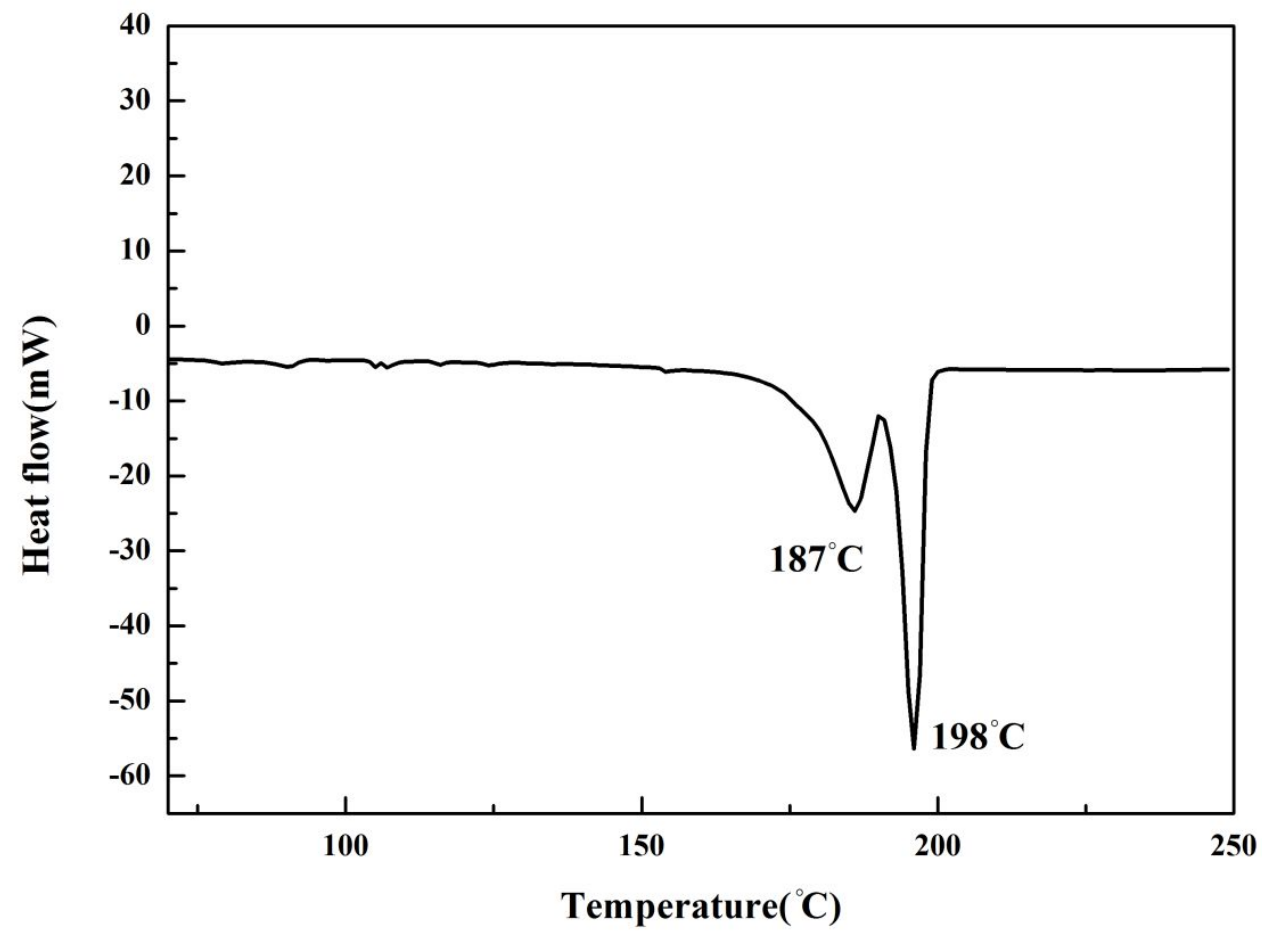

Figure S7. DSC heating curve of crystal-1a. 


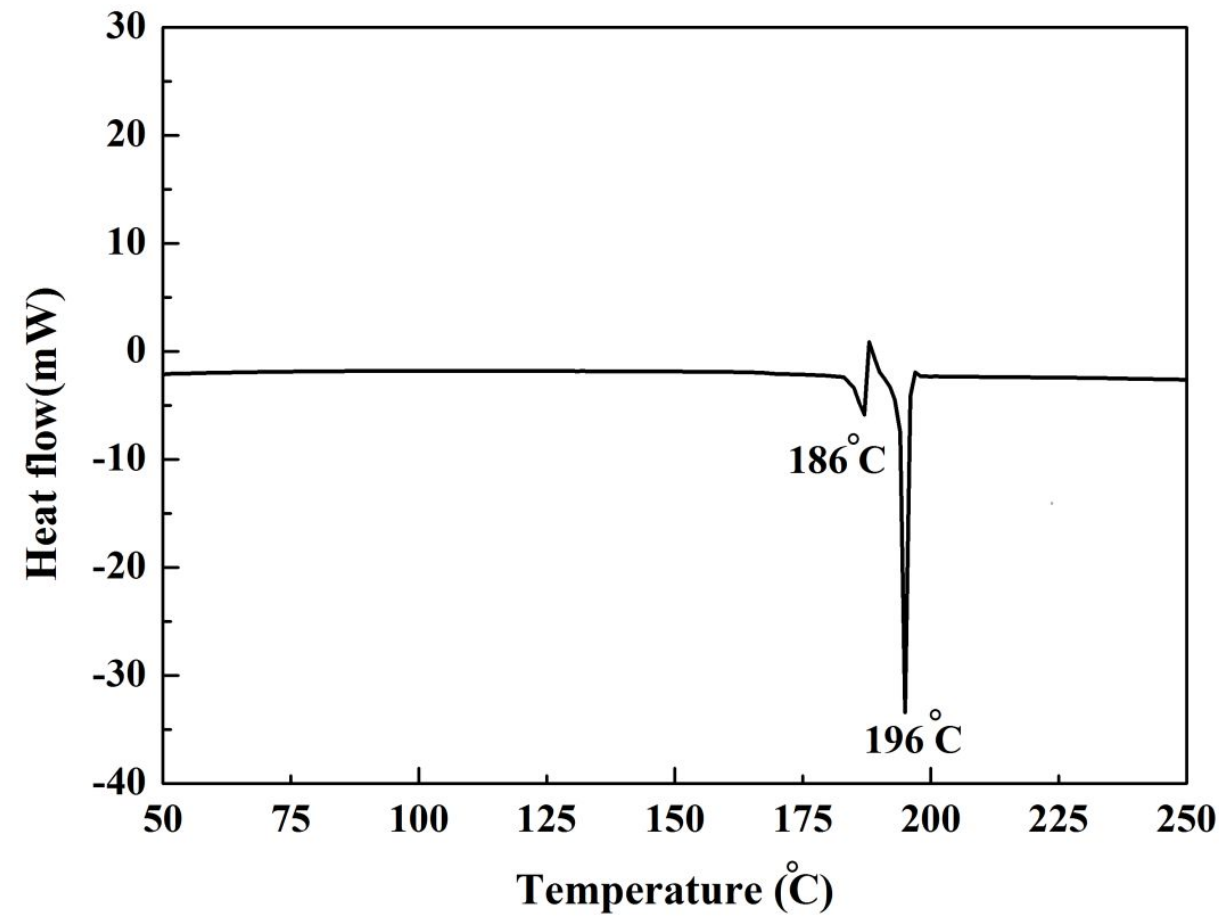

Figure S8. DSC heating curve of crystal $\mathbf{1 b}$.

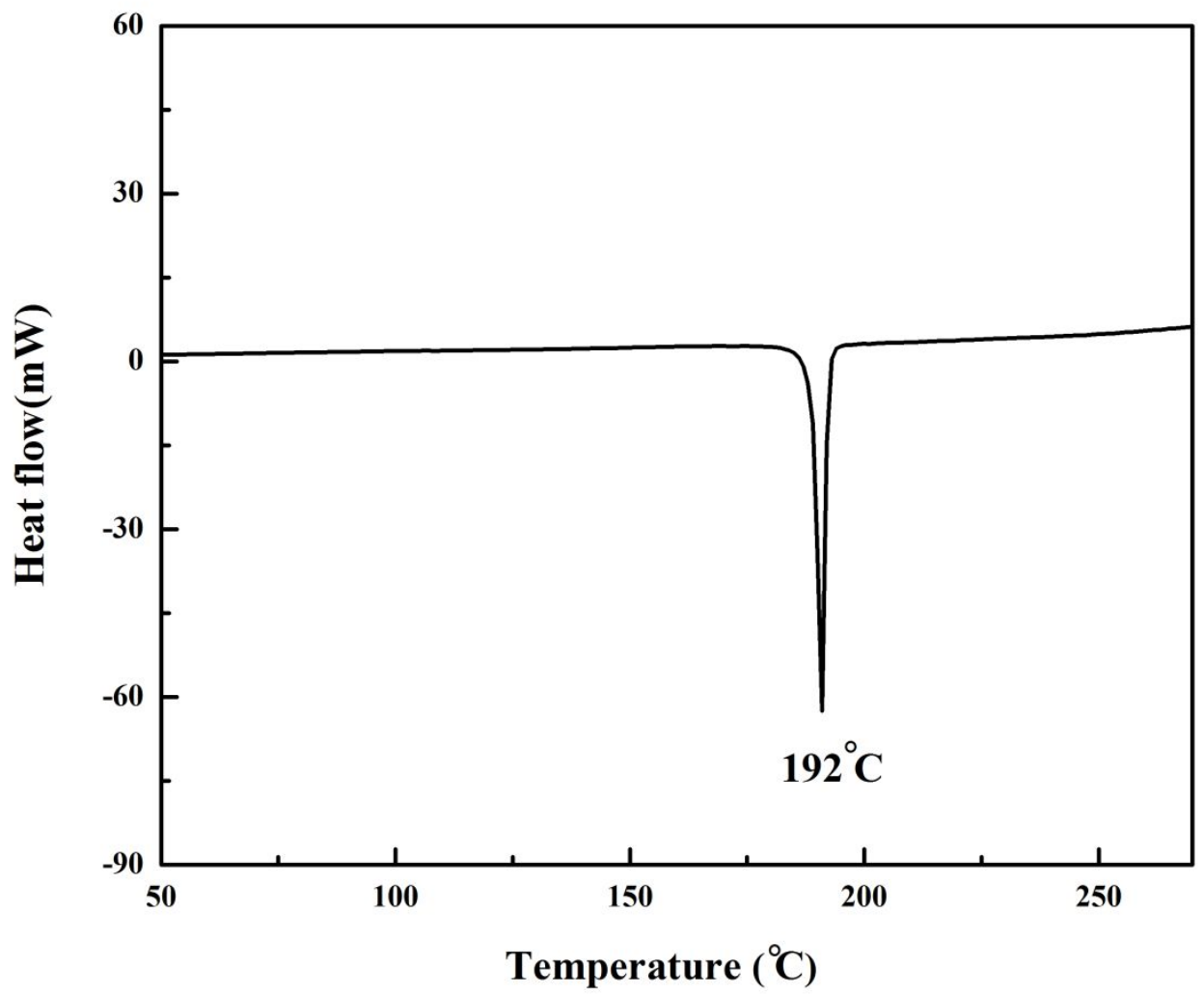

Figure S9. DSC heating curve of crystal 2. 


\section{Thermogravimetric analysis (TGA)}

NETZCH STA 2500 thermogravimeric analyzer was used. Approximately $5 \mathrm{mg}$ of sample was loaded to platinum crucible and heated from 30 to $600{ }^{\circ} \mathrm{C}$ at $10{ }^{\circ} \mathrm{C} / \mathrm{min}$ under nitrogen purge of $60 \mathrm{ml} / \mathrm{min}$.

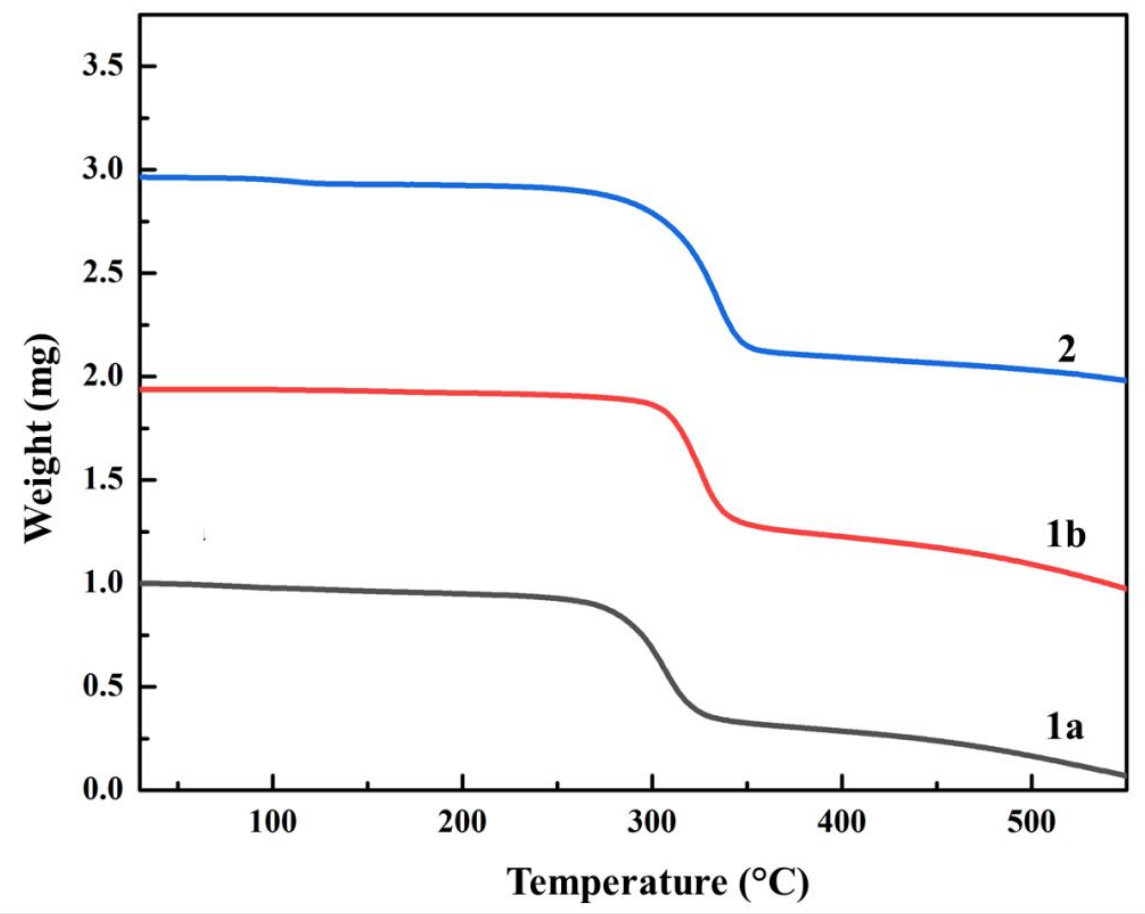

Figure S10. TGA of crystals 1a, 1 b and 2.

\section{Variable Temperature Powder X-ray Diffractometry (variable temperature} XRD)

Powder samples were placed in the copper sample holder of an X-ray diffractometer (D8 Advance, Bruker AXS, Madison, WI) equipped with variable temperature stage (TTK 450, Anton Paar, Graz-Straßgang, Austria) and Si strip one-dimensional detector (LynxEye, Bruker AXS, Madison, WI). The samples were subjected to a controlled temperature program (RT to $170{ }^{\circ} \mathrm{C}$ at $\sim 10^{\circ} \mathrm{C} / \mathrm{min}$, and subsequent heating to $195{ }^{\circ} \mathrm{C}$ at $\left.\sim 5^{\circ} \mathrm{C} / \mathrm{min}\right)$. XRD patterns were collected at RT, $150,160,170,175,180,185$, and $190^{\circ} \mathrm{C}$. Samples were held isothermally during the XRD pattern collection. The XRD patterns were obtained by exposing to Co K $\alpha$ radiation (1.79 $\AA 35 \mathrm{kV} \times 45 \mathrm{~mA})$ over an angular range of 9 to $40^{\circ} 2 \theta$ with a step size of $0.05^{\circ}$ and a dwell time of $0.5 \mathrm{~s}$. The data was converted to $\mathrm{Cu} \mathrm{K \alpha}$ radiation (1.54 $\AA$ ) by using MDI Jade 7.8.2 and analyzed. 


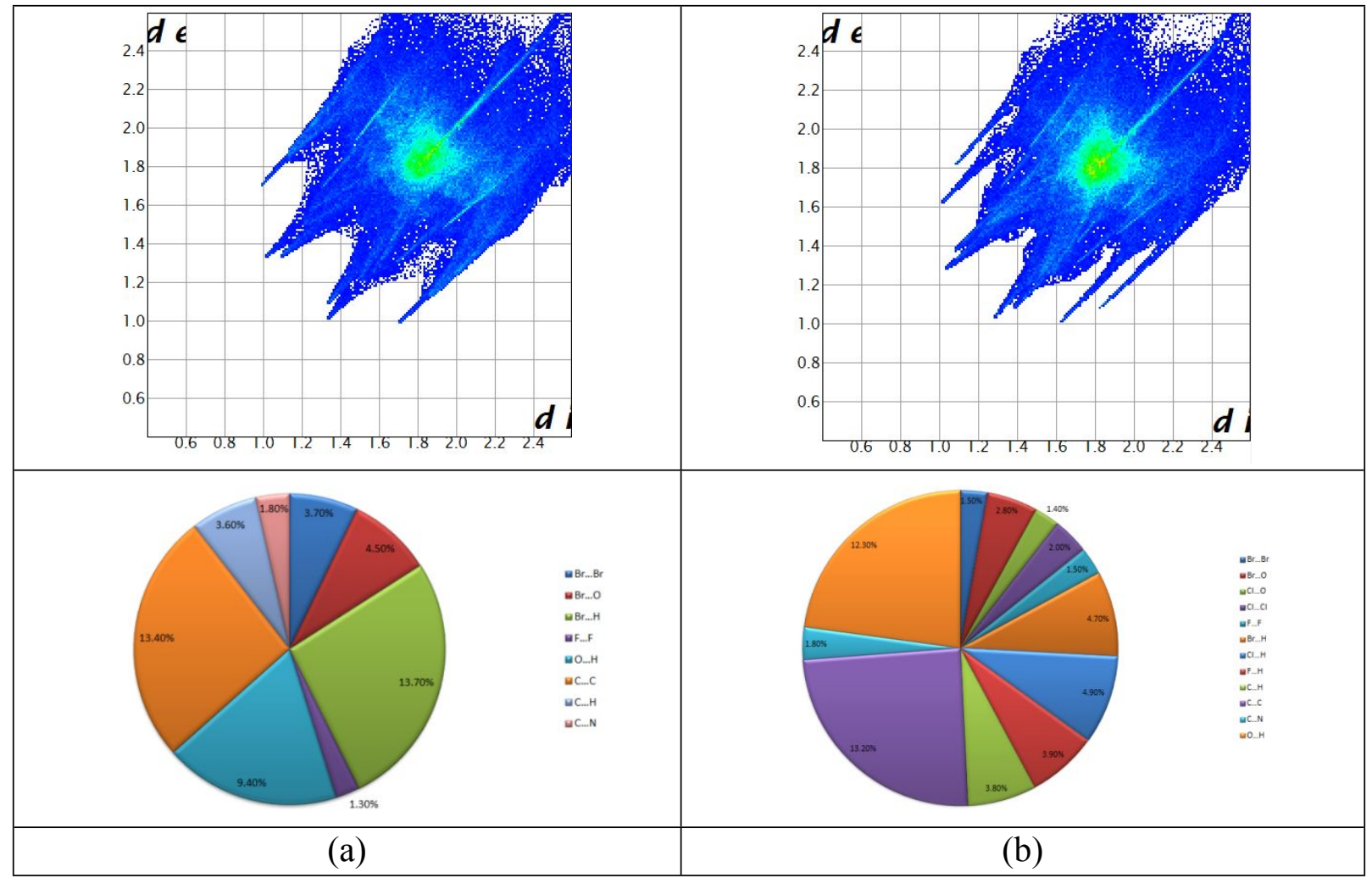

Figure S11. (a) and (b) shows fingerprint plots and percentage contribution of hydrogen/halogen-bonding interactions of $\mathbf{1 b}$ and $\mathbf{2}$, respectively.

\section{Energy framework calculation}

Energy frameworks calculations for intermolecular interactions topologies for crystals $1 \mathrm{a}, 1 \mathrm{~b}$

and 2 were performed using the software suite Crystal-Explorer V.17 based on Gaussian

B3LYP-D2/6-31G(d,p) molecular wavefunctions calculated using .cif files (Table S1). ${ }^{9}$ The

hydrogen positions normalized to standard neutron diffraction values for all the structures were

used during the calculation. For each molecule in the asymmetric unit of a crystal, the total

intermolecular interaction energy with another molecule, calculated using the B3LYP-D2/6- 
$31 \mathrm{G}(\mathrm{d}, \mathrm{p})$ electron densities model, is the sum of electrostatic, polarization, dispersion, and exchange-repulsion components with scaling factors of 1.057, 0.740, 0.871, and 0.618, respectively. The interaction energies of a selected molecule with all molecules having any atom within $3.8 \AA$ were calculated. The interaction energies below a certain energy threshold $(10 \mathrm{~kJ} / \mathrm{mol})$ were omitted for clarity, and the cylinder thickness was taken to be proportional to the strength of intermolecular interaction energies. 


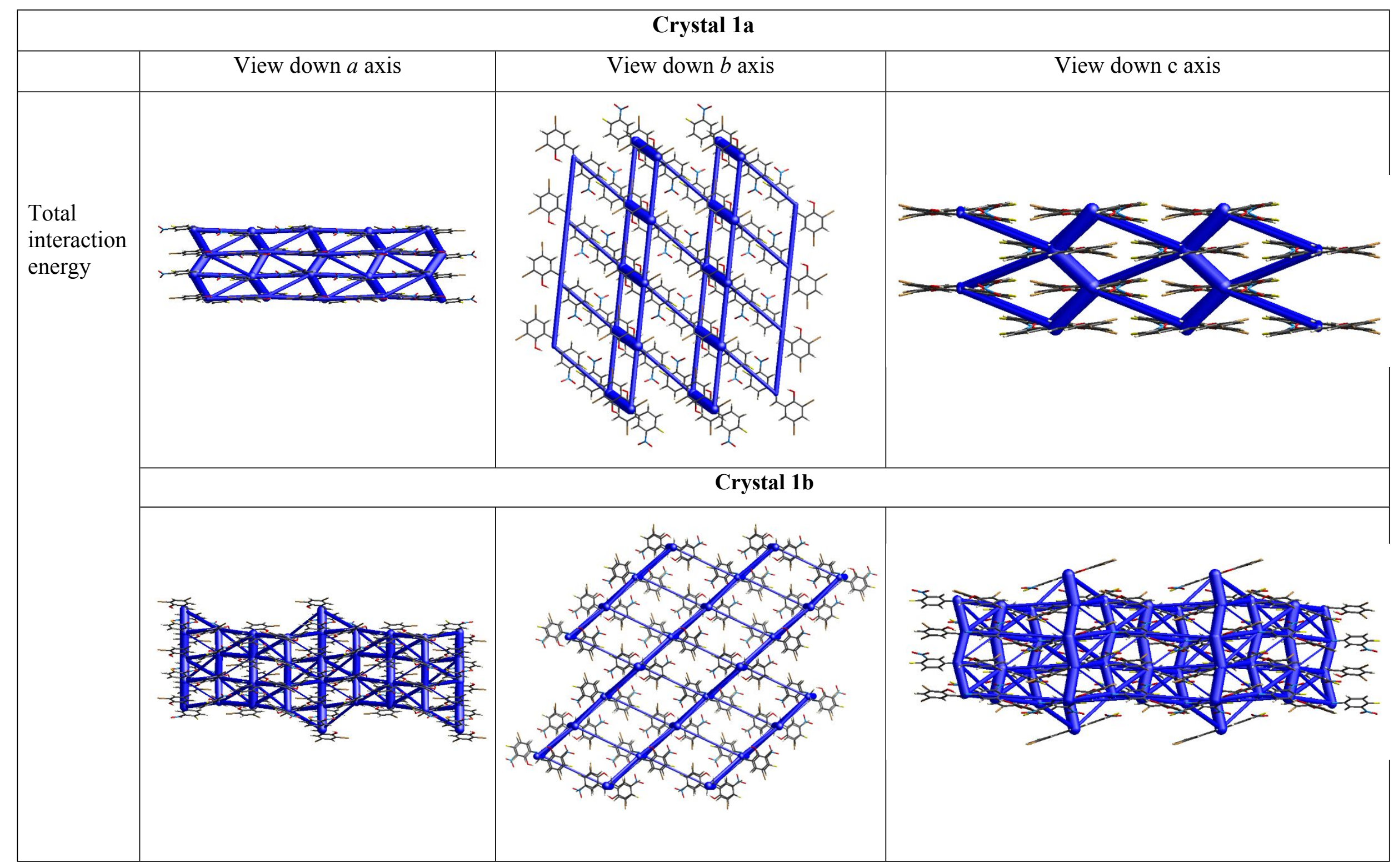




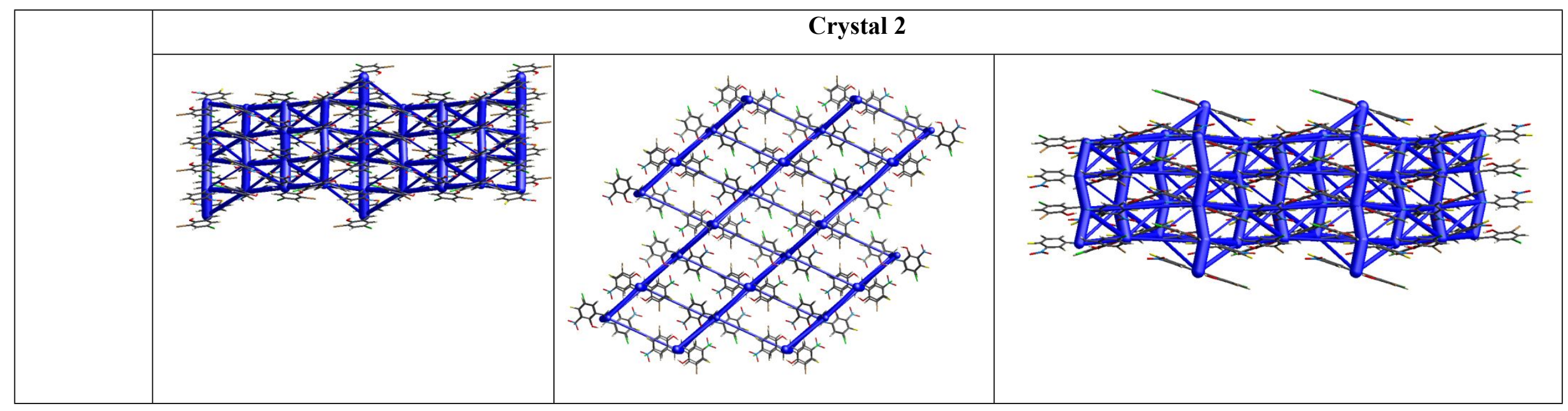

Figure S12. Energy framework calculation of crystals $1 \mathrm{a}, 1 \mathrm{~b}$, and 2.

\section{References:}

1. Software for Chemical Crystallography v2016.10-0, Bruker AXS Inc.: Madison, WI, 2016.

2. Version 8.37A; Bruker AXS Inc: Madison, WI, 2003. Part of the APEX3 v2016.10-0, Bruker AXS Inc.: Madison, WI, 2016. 
3. Version 2016/2; Bruker AXS Inc: Madison, WI, 2003. Part of the APEX3 v2016.10-0, Bruker AXS Inc.: Madison, WI, 2016. Krause, L.; Herbst-Irmer, R.; Sheldrick G.M.; Stalke D. J. Appl. Cryst., 2015, 48, 3-10.

4. Program for the Solution of Crystal Structures. Sheldrick, G. M. SHELXT - Integrated Space-Group and Crystal-Structure Determination. ActaCryst. 2015, A71, 3-8.

5. Program for the Solution and Refining of Crystal Structures. Sheldrick, G. M. A short history of SHELXL. ActaCryst. 2008, A64, 112-122.

6. Hübschle, C. B.; Sheldrick, G. M.; Dittrich, B. ShelXle: A Qt graphical user interface for SHELXL. J. Appl. Crystallogr. $2011,44,1281-1284$.

7. Interactive Molecular Graphics. Part of Program Library for Structure Solution and Molecular Graphics; Bruker AXS, Inc.: Madison, WI, 2000-2013

8. S. Ghosh, M.K. Mishra, S.B. Kadambi, U. Ramamurty, G.R. Desiraju, Designing Elastic Organic Crystals: Highly Flexible Polyhalogenated N-Benzylideneanilines, Angew. Chem. Int. Ed. 54(9) (2015) 2674-2678.

9. Turner, M. J.; McKinnon, J. J.; Wolff, S. K.; Grimwood, D. J.; Spackman, P. R.; Jayatilaka, D.; Spackman, M. A. CrystalExplorer17. http://hirshfeldsurface.net 